\title{
Helicobacter pylori independent chronological change in gastric acid secretion in the Japanese
}

\author{
Y Kinoshita, C Kawanami, K Kishi, H Nakata, Y Seino, T Chiba
}

Division of

Gerontology,

Department of

Medicine, Kobe

University School of

Medicine, 7-5-1,

Kusunoki-cho,

Chuo-ku, Kobe 650,

Japan

Y Kinoshita

H Nakata

Division of

Gastroenterology and

Hepatology,

Department of

Medicine

C Kawanami

K Kishi

T Chiba

Department of

Metabolism and

Clinical Nutrition,

Kyoto University,

Graduate School of

Medicine, Kyoto, Japan

Y Seino

Correspondence to:

Dr Y Kinoshita.

Accepted for publication 24 June 1997

\begin{abstract}
Background-Gastric acid secretion in Japanese subjects decreases with aging. One of the possible causative mechanisms of this attenuated acid secretion is speculated to be a Helicobacter pylori induced chronic gastritis. The infection rate of this microorganism has decreased recently in Japan.

Aims-To investigate whether gastric acid secretion has altered over the past 20 years, and if so, what the influence of $H$ pylori infection might be in the Japanese population.

Subjects and methods-Gastric acid secretion, serum gastrin and pepsinogen I and $I I$ concentrations, and $H$ pylori infection were determined in 110 Japanese subjects in both the 1970s and 1990s.

Results-Basal acid output as well as maximal acid output have greatly increased over the past 20 years, not only in individuals with $H$ pylori infection but also in those without infection. Furthermore, subjects with $H$ pylori infection tended to show decreased gastric acid secretion in comparison with those without infection, particularly in geriatric subjects. There was a positive correlation between gastric acid secretion and serum pepsinogen I concentrations.

Conclusions-In Japan, both basal and stimulated gastric acid secretion have increased over the past 20 years; some unknown factors other than the decrease in $H$ pylori infection may play an important role in this phenomenon.

(Gut 1997; 41: 452-458)
\end{abstract}

Keywords: gastric acid; Helicobacter pylori; aging; gastrin

Gastric acid secretion is under the control of various factors including race, sex, and age. In Western countries, the level of gastric acid secretion is reported to be maintained with aging. ${ }^{1-4}$ On the other hand, acid secretion decreases in the elderly in Japan due to encroaching atrophic gastritis. ${ }^{56}$ In Japan, the rate of Helicobacter pylori infection is very high with a resulting higher incidence of gastritis and gastric mucosal atrophy. ${ }^{5-10}$ The decrease in acid secretion with chronological aging in Japan may therefore result from $H$ pylori infection. It is not clear at present however whether $H$ pylori is the sole factor responsible for the decrease in acid secretion with aging. Furthermore, the infection rate of $H$ pylori has recently been reported to be decreasing in Japan as well as in other countries. ${ }^{112}$

With these conflicting factors in mind, we have investigated whether gastric acid secretion has altered over the past 20 years with and without the influence of $H$ pylori infection in the Japanese, both non-elderly and elderly.

\section{Materials and Methods}

\section{MATERIALS}

One hundred and ten healthy volunteers in the Amagasaki area were used for the analysis. One group comprised normal individuals whose gastric acid secretion had been investigated in the early 1970s. The other group was investigated in the early 1990s. Male:female ratios, social class, and dietary habits of the volunteers were similar between the groups. Each group was further subdivided into four groups by age and the presence or absence of $H$ pylori infection. Accordingly, eight groups were analysed and compared (table 1). Individuals with a history of peptic ulcer, gastric surgery, malignancy, renal failure, or other gastrointestinal diseases were excluded. Subjects being treated with drugs known to affect gastric secretion were also excluded.

Written consent was obtained from all individuals. The study was approved by the institutional ethical committee.

MEASUREMENT OF GASTRIC ACID SECRETION Gastric acid secretion was measured at 0800 hours after a 12 hour fast. Gastric tubing with multiple openings was inserted into the stomach and gastric juice was aspirated. After insertion of the tubing, basal acid output (BAO) was measured by titrating the acidity of the gastric juice collected during the basal condition for one hour. Maximal acid output (MAO) was then measured by administrating $6 \mu \mathrm{g}$ pentagastrin (Zeneca Pharmaceutical Co. Ltd, Osaka, Japan) intramuscularly and collecting the gastric juice for an additional hour as a sum of six 10 minute outputs after pentagastrin injection. ${ }^{13}$ 

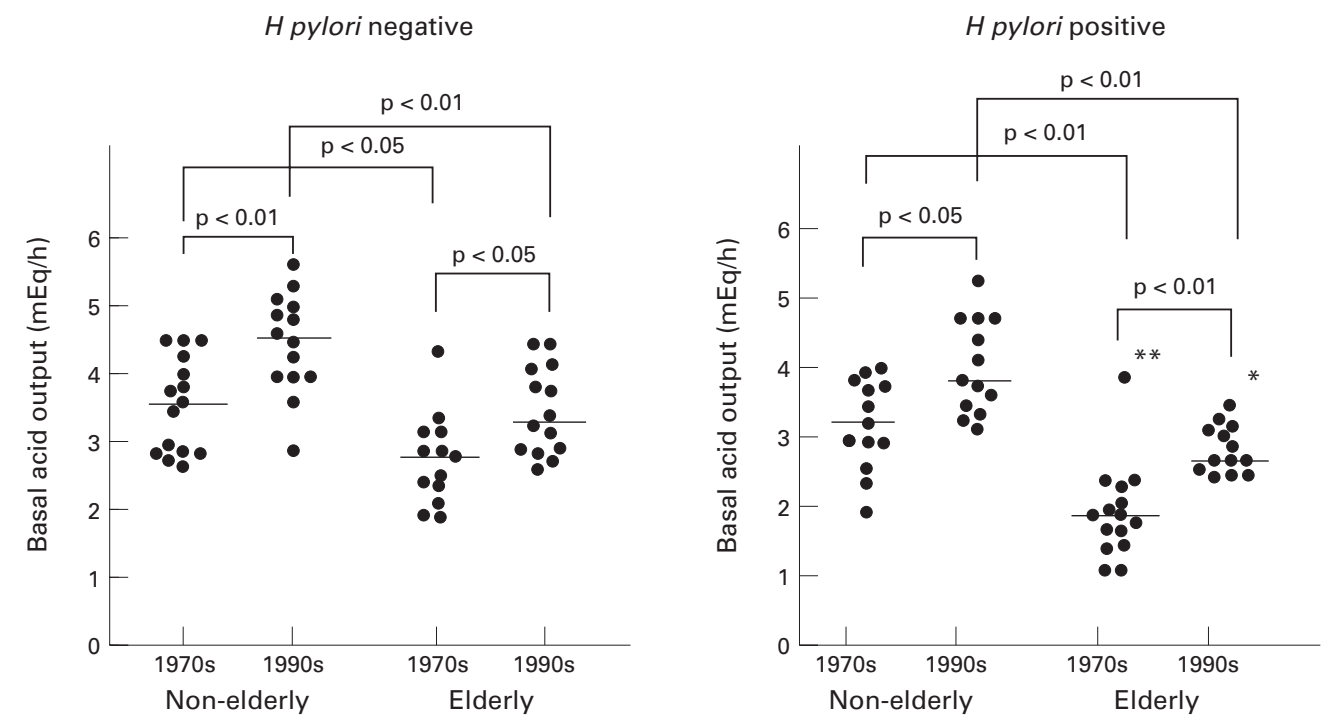

Figure 1: BAO in the eight groups. Each dot represents a single case. Horizontal lines indicate medians of individual groups. ${ }^{\star *}$ Significant difference $\left(p<0.01\right.$ ) between $H$ pylori positive and negative groups (group 7 v group 3); ${ }^{\star}$ significant difference $(p<0.05)$ between $H$ pylori positive and negative groups (group 8 v group 4 ).

ASSAY OF SERUM GASTRIN, H PYLORI ANTIBODY, AND PEPSINOGEN I AND II

Blood samples were obtained early in the morning. Serum was separated and stored at $-80^{\circ} \mathrm{C}$ until the assay. Serum gastrin concentrations were measured by radioimmunoassay (Gastrin Riakit II, Dainabot Co. Ltd, Tokyo, Japan). ${ }^{14}$ Anti-H pylori IgG antibody was measured by the HM-CAP immunoassay (Determiner Helicobacter, Enterle Products Inc., Westbury, New York, USA). ${ }^{15-17}$ This assay system is reported to have $98.7 \%$ sensitivity and $100 \%$ specificity in a Western country ${ }^{18}$ and $100 \%$ sensitivity and $96 \%$ specificity in Japan in comparison with the urea breath test. ${ }^{7} \mathrm{~A}$ cut off optical density of 0.30 was chosen according to Asaka et al. ${ }^{7}$ Serum pepsinogen I and II concentrations were also measured by radioimmunoassay (Dainabot Co. Ltd, Tokyo, Japan) as possible indicators of the histological status of the gastric mucosa. ${ }^{14} 1920$

STATISTICAL ANALYSIS

Comparisons were made by Stat View 4.0 software (Abacus Concepts, Inc., Berkeley, California, USA) using a non-parametric MannWhitney $\mathrm{U}$ test. Linear regression analysis was performed by the same software.

TABle 1 Patient details

\begin{tabular}{llllll}
\hline Group & H pylori status & Young/old $t$ & $\begin{array}{l}\text { Years } \\
\text { investigated } \neq\end{array}$ & AgeS & M/F \\
\hline 1 & Negative & Non-elderly & $1970 \mathrm{~s}$ & $50(3)$ & $8 / 7$ \\
2 & Negative & Non-elderly & $1990 \mathrm{~s}$ & $48(3)$ & $7 / 7$ \\
3 & Negative & Elderly & $1970 \mathrm{~s}$ & $76(1)$ & $6 / 6$ \\
4 & Negative & Elderly & $1990 \mathrm{~s}$ & $76(2)$ & $7 / 7$ \\
5 & Positive & Non-elderly & $1970 \mathrm{~s}$ & $46(3)$ & $7 / 6$ \\
6 & Positive & Non-elderly & $1990 \mathrm{~s}$ & $48(3)$ & $7 / 6$ \\
7 & Positive & Elderly & $1970 \mathrm{~s}$ & $75(2)$ & $7 / 9$ \\
8 & Positive & Elderly & $1990 \mathrm{~s}$ & $76(2)$ & $6 / 7$
\end{tabular}

^Antibody against $H$ pylori present (positive) or absent (negative).

†Non-elderly ( $<65$ years); elderly ( $>65$ years).

$\$ 1970$ s (1971-5); 1990s (1991-5).

$§$ Results are expressed as mean (SEM).

\section{Results}

Age distribution among groups 1, 2, 5, and 6, and among groups 3, 4, 7, and 8 was not significantly different (table 1). Sex distribution was not different among all the groups. Gastric acid secretion in elderly subjects was lower than that in non-elderly individuals both in the 1970s and 1990s, irrespective of the presence of $H$ pylori infection (figs 1 and 2). When the effect of $H$ pylori infection on gastric acid secretion was investigated for each period, the infection decreased BAO and MAO both in the 1970 s and 1990 s and mainly in elderly persons (figs 1 and 2).

When the data obtained in the 1970 s were compared with data from the 1990s, it was confirmed that acid secretion in the 1990s was higher in both the non-elderly and elderly, regardless of $H$ pylori infection (figs 1 and 2). While both BAO and MAO were elevated in the 1990s, the increase in MAO was more prominent than that of BAO. Therefore, MAO:BAO ratios in elderly individuals, for example, have increased from 3.28 to 4.25 $(\mathrm{p}<0.01)$ in $H$ pylori negative individuals and from 3.69 to $4.04(\mathrm{p}<0.05)$ in $H$ pylori positive subjects over the past 20 years (table 2). Although the differences did not reach statistically significant levels, a similar increase in the MAO:BAO ratio was also observed in nonelderly individuals. These observations indicated that not only basal gastric acid secretion but also the responsiveness of acid secretion to pentagastrin has increased over the past 20 years in Japan.

Serum gastrin concentrations in $H$ pylori positive elderly subjects were however higher than in non-elderly subjects, both in the 1970 s and 1990s. In H pylori negative subjects, gastrin concentrations in the elderly were greater than those in non-elderly subjects only in the 1970 s (fig 3). Although $H$ pylori infection tended to increase serum gastrin concentrations in both the 1970s and 1990s, irrespective of age, the 
TABLE 2 MAO:BAO ratio in the eight groups

\begin{tabular}{llr}
\hline Group & MAO:BAO ratio & Gastrin $(p g / m l)$ \\
\hline 1 & $3.77(0.14)$ & $81.8(5.7)$ \\
2 & $4.12(0.17)$ & $92.7(4.4)$ \\
3 & $3.28(0.14)$ & $104.8(5.6)$ \\
4 & $4.25(0.20)$ & $102.0(5.7)$ \\
5 & $3.82(0.26)$ & $88.4(6.0)$ \\
6 & $3.90(0.07)$ & $93.9(4.8)$ \\
7 & $3.69(0.31)$ & $114.1(3.5)$ \\
8 & $4.04(0.06)$ & $114.0(4.8)$ \\
\hline
\end{tabular}

Differences in the MAO:BAO ratio were significant between groups 3 and $4(p<0.01)$ and groups 7 and $8(p<0.05)$.

Differences in gastrin concentrations were significant between groups 1 and $3(\mathrm{p}<0.01)$, groups 5 and $7(\mathrm{p}<0.01)$, and groups 6 and $8(\mathrm{p}<0.05)$.

difference did not reach statistically significant levels (fig 3).

There was a negative correlation between BAO and serum gastrin in the 1970s $(r=-0.61$, $\mathrm{p}<0.05)$ and also in the 1990s $(r=-0.56$, $\mathrm{p}<0.05)$. When the correlations between these two parameters were compared, it was clear

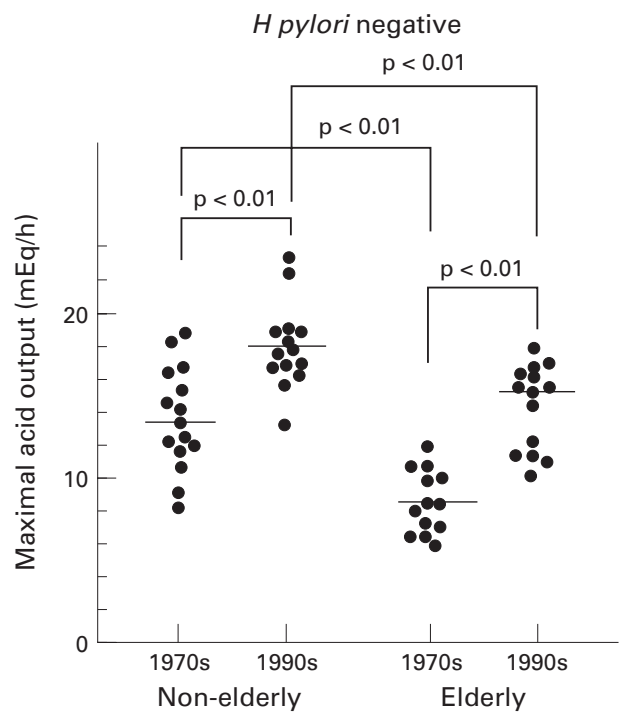

that basal acid secretion in the 1990s was higher than that in the 1970s in spite of almost the same concentrations of gastrin (fig 4).

Serum pepsinogen I concentrations were higher in the 1990s than in the 1970s, irrespective of age and $H$ pylori infection (fig 5). In $H$ pylori positive subjects, the elderly showed lower pepsinogen I concentrations than non-elderly subjects. Pepsinogen II concentrations, however, were higher in $H$ pylori positive subjects than in $H$ pylori negative individuals not only in the 1970s but also in the 1990s, irrespective of the age of the subjects (fig 6). This result confirmed the reports by Hunter et $a l^{21}$ and Wagner et $a l .{ }^{22}$ There was a strong positive correlation between serum pepsinogen $\mathrm{I}$ and gastric acid secretion (BAO: $r=0.71, \mathrm{p}<0.01$; MAO: $r=0.79, \mathrm{p}<0.01$ ) as shown in fig 7 .

One additional interesting observation is the difference in acid secretion between male and female subjects. Both the BAO and MAO of

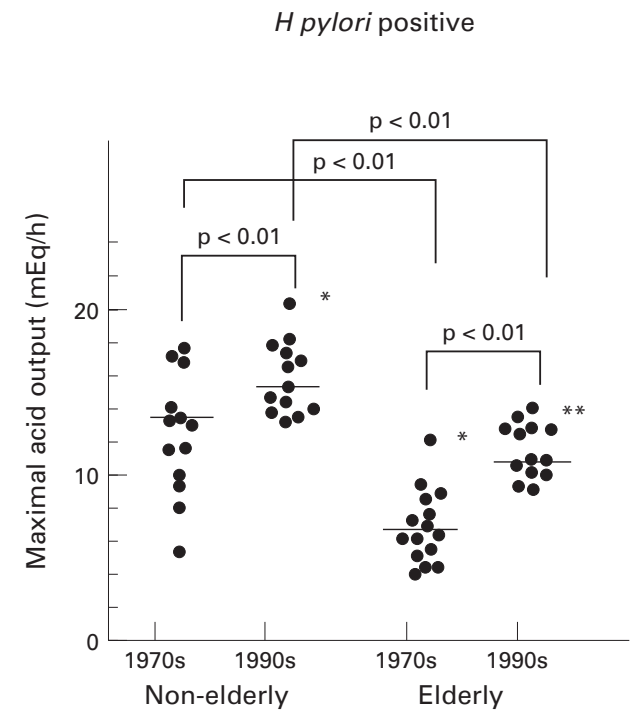

Figure 2: $\quad$ MAO in the eight groups. Each dot represents a single case. Horizontal lines indicate medians of individual groups. ${ }^{\star}$ Significant difference $(p<0.01)$ between H pylori positive and negative groups (group 8 v group 4); ${ }_{\text {significant }}$ difference $(p<0.05)$ between H pylori positive and negative groups (group $6 v$ group 2 , and group $7 v$ group 3 ).

H pylori negative

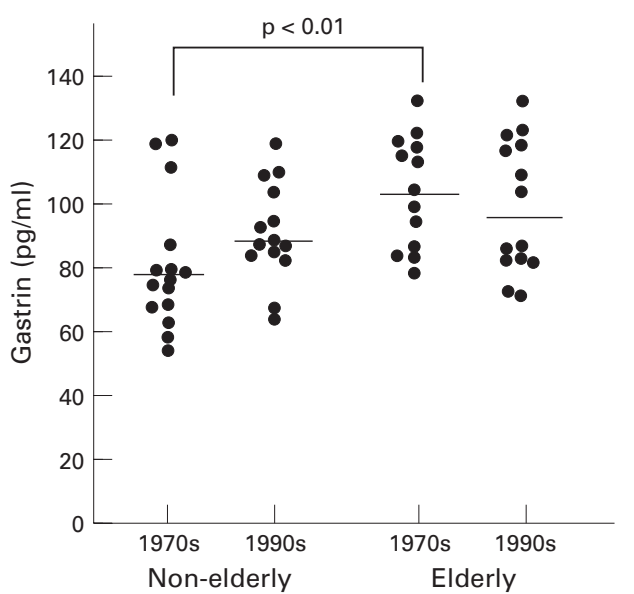

H pylori positive

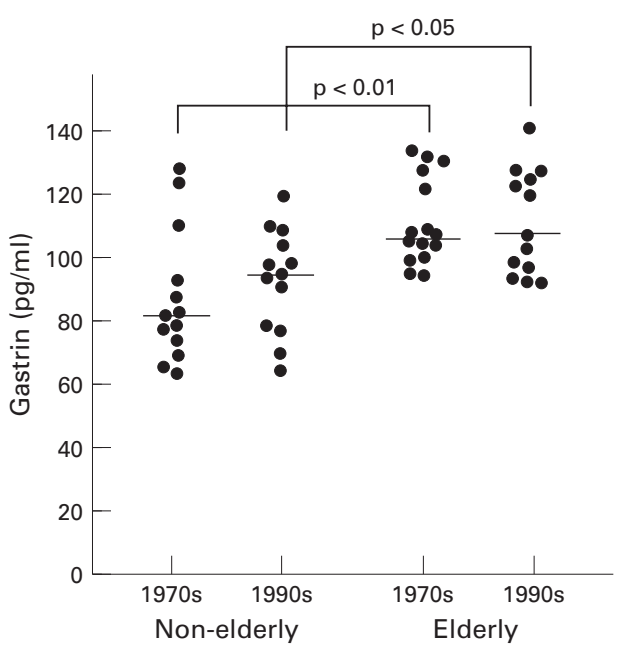

Figure 3: Serum gastrin concentrations in the eight groups. Each dot represents a single case. Horizontal lines indicate medians of individual groups. 

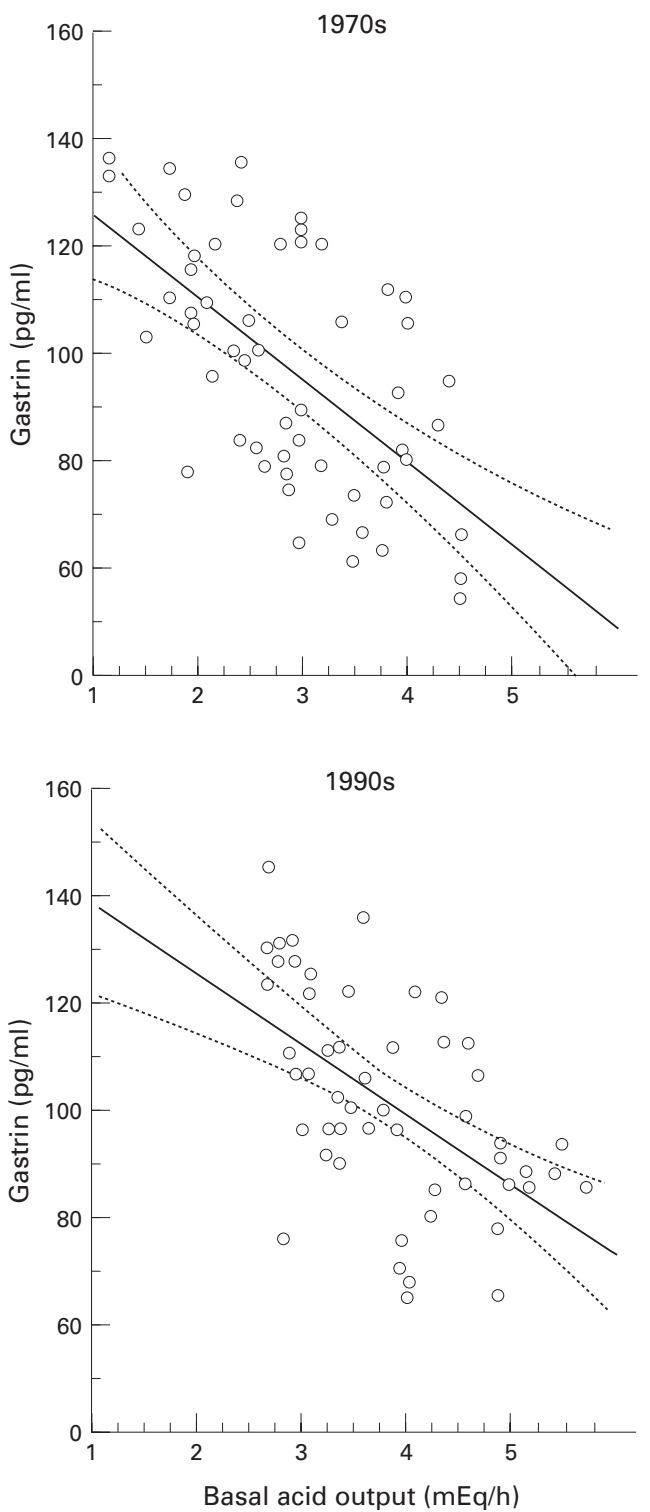

Figure 4: Correlation between serum gastrin concentrations and BAO in the 1970s and 1990s. Each dot represents a single case. Solid lines represent the regression plots; dotted lines represent $95 \%$ confidence bands.

female groups were higher than those of male groups, mainly in elderly persons irrespective of $H$ pylori infection (table 3 ).

\section{Discussion}

The observations that gastric acid secretion decreases with aging in Japan is in sharp contrast to the observations reported from many Western countries. ${ }^{1-6}$ The causative mechanism of the decreased acid secretion in elderly persons has been attributed to a higher prevalence of $H$ pylori infection in Japan in comparison with that in Western countries..$^{7-10}$ Indeed, in one Western country, a group of elderly subjects with a very high positive rate of $H$ pylori infection $(81.8 \%$ antibody positive rate) was reported to show decreased gastric acid secretion in response to the injection of gastrin. ${ }^{23}$ Infection with $H$ pylori causes chronic inflammation in the gastric mucosal tissue with resulting atrophy of the gastric gland. ${ }^{24-26}$ This atrophy is believed to be a major cause of the decreased acid secretion in the elderly. ${ }^{27}$ This study clearly demonstrated decreases in BAO and MAO in elderly subjects in the 1970s as well as in the 1990s, confirming previous reports in Japan. ${ }^{56}$

The interesting point to be noted in this study is that even in non-infected elderly subjects, there was lower acid secetion than in younger subjects. These data suggest the presence of factors other than $H$ pylori which decrease acid secretion. This concept is also supported by the work of Satoh et $a l^{28}$ and Schlewper et al. ${ }^{29}$ Satoh et al found a positive correlation between age and extent of endoscopy proven atrophic gastritis in both $H$ pylori positive and negative patients. Schlewper et al clearly suggested the presence of $H$ pylori unrelated atrophic gastritis in the Japanese in their comparison of Japanese and Dutch working populations.

In most subjects, infection with $H$ pylori is believed to be established in childhood and at least by the age of 40 years in Japan, and the infection continues until its termination by administration of a large amount of antibiotics. ${ }^{7}$ Several methods are available to detect the presence of infection. ${ }^{30} 31$ The detection of IgG antibody to $H$ pylori in serum, which was used in this study, is one of the most sensitive and specific methods available. ${ }^{7} 18$ 30-32 Furthermore, detection by this method is not influenced by the patchy distribution of this microorganism in the stomach, often observed in the elderly. This method was the only way to determine possible infection with $H$ pylori in subjects whose gastric acid secretion was investigated in the 1970s. In subjects with advanced gastric atrophy and achlorhydria, the titre of serum anti- $H$ pylori antibody may fall off and become seronegative in the course of developing more severe atrophic gastritis. There is a possibility therefore that some subjects in the $H$ pylori negative group, especially those tested in the 1970 s, may in fact be false negatives. It is not likely, however, that many false negative subjects were included in the $H$ pylori negative groups in this study. Our subjects had high serum pepsinogen I concentrations. Especially in subjects classified into the $H$ pylori negative groups, no subject had a serum pepsinogen I concentration below $30 \mathrm{ng} / \mathrm{ml}$. This clearly showed the absence of cases of severe atrophic gastritis in this study. ${ }^{19}{ }^{20}$ Furthermore, several papers from Japan and Western countries have shown that subjects who had developed progressive atrophic gastritis remained $H$ pylori seropositive, although the $H$ pylori infection rate as measured by staining of gastric biopsy specimens declined with increasing atrophy. ${ }^{33-35}$ Thus, the immunoassay of anti- $H$ pylori antibody, which has high sensitivity (over 98\%) and specificity (over 96\%) not only in Western countries but also in Japan, may be reliable enough to detect gastric $H$ pylori infection in this study.

When the effects of $H$ pylori infection on $\mathrm{BAO}$ and MAO were tested, the infection was demonstrated to decrease gastric acid secretion mainly in the elderly. This is quite reasonable, 
since a possibly long lasting infection in elderly persons should cause higher grade atrophy of the gastric glands with a resulting decrease in gastric acid secretion. Furthermore, several recent studies indicated that a decrease in gastric acid secretion accelerates colonisation of the fundic gland mucosa by $H$ pylori leading to the induction of corpus gastritis and a further decrease in acid secretion. ${ }^{36-38}$

When acid secretion was compared between the 1990 s and 1970s, it was clearly shown to be augmented in the 1990s. It should be emphasised that the augmentation of gastric acid secretion was not influenced by $H$ pylori infection. Even in the individuals without $H$ pylori infection, the increased acid secretion was observed in the 1990 s both in the young and old. It is evident therefore that the increase in acid secretion over these past 20 years has been caused not only by the decreased infection rate of $H$ pylori but also by some unknown factors. Although this additional modifying factor has not been identified, the improvement in gastric acid secretion over 20 years may be related to changes in dietary habits in Japan. There has been a remarkable increase in dietary fat intake and a modest increase in protein consumption over the past 20 years. ${ }^{39}$ High dietary fat is a

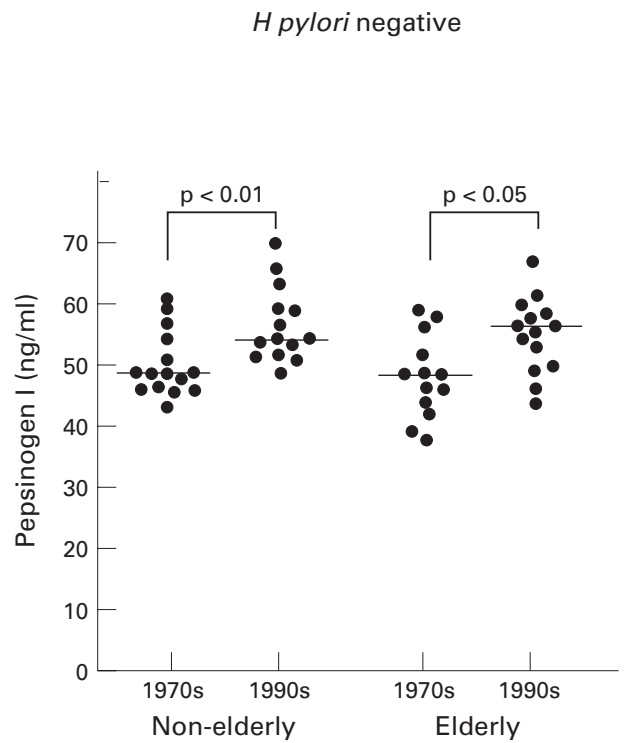

well known risk factor for colorectal cancers. ${ }^{40}$ With the increased consumption of fat in Japan, we have observed a remarkable increase in the number of patients suffered from colorectal cancers. ${ }^{41}$ The changes in dietary habits, especially the increased consumption of fat, may therefore be a possible factor influencing the change in acid secretion.

Although the causative mechanism of increased acid secretion in the past 20 years in Japan is not fully understood, our data confirmed the presence of a strong positive correlation between gastric acid secretion and serum pepsinogen I concentrations. Our data also indicated that pepsinogen I concentrations in the $1990 \mathrm{~s}$ were higher than those in the 1970s. As serum pepsinogen I is known to be a good predictive indicator of gastric mucosal atrophy, the attenuated gastric mucosal atrophy in the 1990s may be a factor which is related to the increased acid secretion. ${ }^{19} 20$

It should be mentioned that gastric acid secretion in Japanese subjects is still lower than that in Europeans and Americans, even in the 1990s. ${ }^{4}$ As $H$ pylori is reported to induce chronic gastritis more easily in subjects with decreased acid secretion, ${ }^{25} 42$ the low gastric acid secretion in the Japanese may be one of the

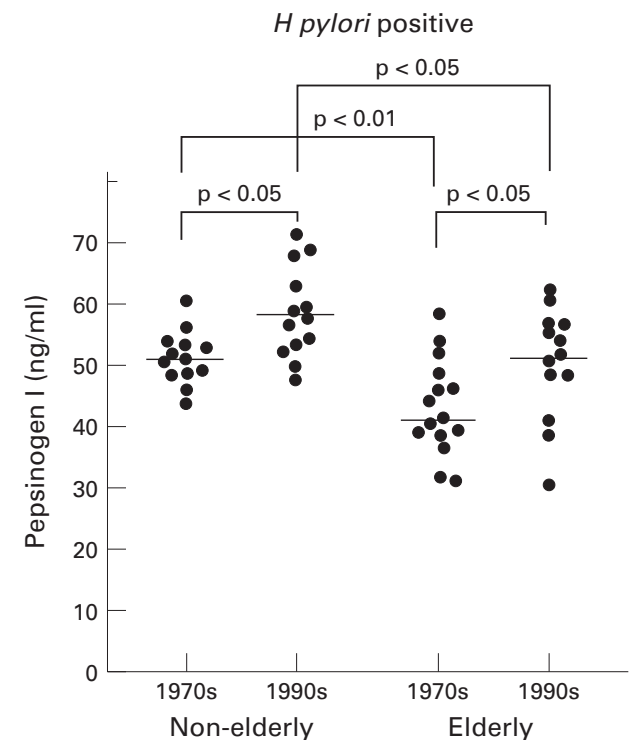

Figure 5: Serum pepsinogen I concentrations in the eight groups. Each dot represents a single case. Horizontal lines indicate medians of individual groups.
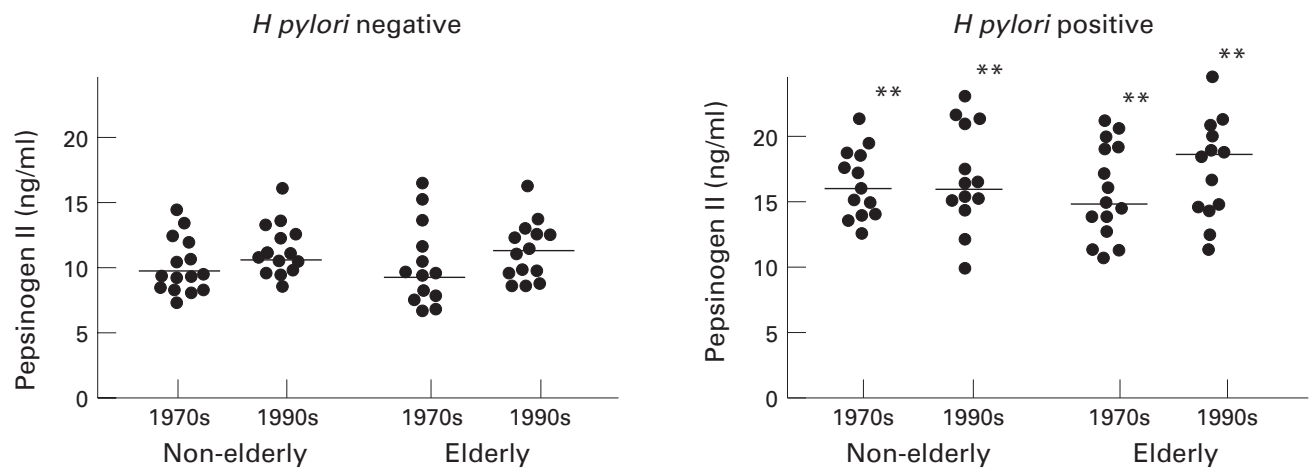

Figure 6: Serum pepsinogen II concentrations in the eight groups. Each dot represents a single case. Horizontal lines indicate medians of individual groups. ${ }^{*}$ Significant difference $(p<0.01)$ between $H$ pylori positive and negative groups (group 5 v group 1, group 6 v group 2, group 7 v group 3, and group 8 v group 4). 

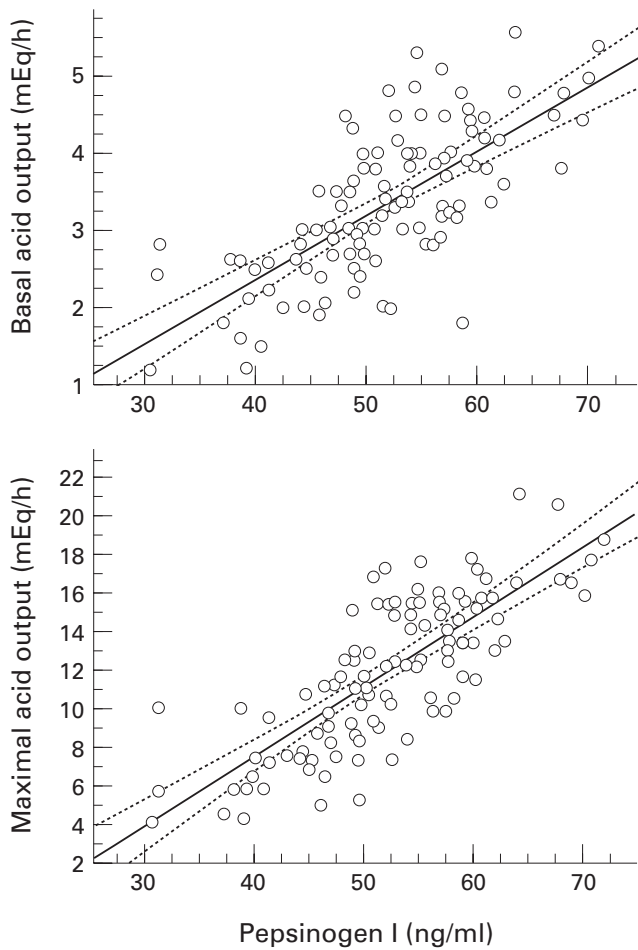

Figure 7: Correlation between serum pepsinogen I concentrations and gastric acid secretion. Each dot indicates a single case. Solid lines represent the regression plots; dotted lines represent $95 \%$ confidence bands.

causative factors of the higher incidence of $H$ pylori infection and atrophic gastritis in Japan. On the other hand, elevated gastric acid secretion is reported frequently to cause gastric metaplasia in the duodenum. ${ }^{44}{ }^{45}$ This metaplastic epithelium is vulnerable to $H$ pylori infection with resulting ulcer formation in the duodenum. The higher duodenal ulcer:gastric ulcer ratio in Western countries than in Japan may therefore be due to $H$ pylori infection of the metaplastic gastric epithelium in the duodenum where the acid is stronger than in the Japanese. ${ }^{46}$

When gastric acid secretion in response to endogenous gastrin was investigated, it became clear that larger amounts of acid were secreted in response to the same concentrations of serum gastrin in the $1990 \mathrm{~s}$. This result

TABLE 3 Gastric acid secretion in men and women

\begin{tabular}{llllll}
\hline Group & Sex & Number & Age & BAO(mEq/h) & MAO(mEq/h) \\
\hline 1 & $\mathrm{M}$ & 8 & $52(4)$ & $3.4(0.3)$ & $13.3(1.6)$ \\
2 & $\mathrm{~F}$ & 7 & $47(3)$ & $3.7(0.3)$ & $13.8(0.7)$ \\
& $\mathrm{M}$ & 7 & $48(4)$ & $4.3(0.4)$ & $17.5(1.2)$ \\
3 & $\mathrm{~F}$ & 7 & $48(5)$ & $4.6(0.2)$ & $18.9(0.8)$ \\
& $\mathrm{M}$ & 6 & $76(2)$ & $2.3(0.1)$ & $7.4(0.3)$ \\
4 & $\mathrm{~F}$ & 6 & $75(3)$ & $3.3(0.3)$ & $10.7(0.6)$ \\
& $\mathrm{M}$ & 7 & $75(3)$ & $3.1(0.2)$ & $13.6(1.0)$ \\
5 & $\mathrm{~F}$ & 7 & $76(2)$ & $4.0(0.2)$ & $16.0(0.8)$ \\
& $\mathrm{M}$ & 7 & $48(4)$ & $3.0(0.3)$ & $11.0(1.6)$ \\
6 & $\mathrm{~F}$ & 6 & $45(4)$ & $3.5(0.2)$ & $14.1(1.2)$ \\
7 & $\mathrm{M}$ & 7 & $52(4)$ & $3.8(0.3)$ & $14.9(1.1)$ \\
& $\mathrm{F}$ & 6 & $43(5)$ & $4.5(0.2)$ & $17.1(0.4)$ \\
8 & $\mathrm{M}$ & 7 & $75(2)$ & $1.6(0.4)$ & $5.7(0.6)$ \\
& $\mathrm{F}$ & 9 & $75(2)$ & $2.5(0.2)$ & $8.9(0.7)$ \\
& $\mathrm{M}$ & 6 & $76(3)$ & $2.8(0.1)$ & $10.9(0.7)$ \\
& $\mathrm{F}$ & 7 & $77(2)$ & $3.1(0.1)$ & $13.0(0.6)$ \\
\hline
\end{tabular}

Results are expressed as mean (SEM).

Differences in BAO were significant between men and women in groups 3, 4, and $7(\mathrm{p}<0.01)$, and in groups 6 and $8(\mathrm{p}<0.05)$. Differences in MAO were significant between men and women in group $3(\mathrm{p}<0.01)$, and in groups 6,7 , and $8(\mathrm{p}<0.05)$. suggested the higher responsiveness of parietal cells to gastrin or the presence of increased parietal cell mass in the 1990s in comparison with that in the 1970s. Although gastrin is a potent endogenous secretagogue for acid secretion, this result suggests that the response of gastric fundic glands to gastrin could be influenced by factors such as $H$ pylori infection, chronological age, and the era when the investigation was done.

Reflux oesophagitis and peptic ulcer diseases are more frequently found in elderly women than in elderly men in Japan. ${ }^{46}{ }^{47}$ This is speculated to be due to the higher gastric acid secretion in women. Our data support this idea and confirmed that gastric acid secretion is higher in women than in men, especially in the elderly, irrespective of the presence or absence of $H$ pylori infection. This is in sharp contrast to the data reported from many Western countries, where gastric acid secretion is reported to be higher in men than in women. ${ }^{134}$ The lower acid secretion in elderly men observed in this study may therefore be due to factors other than $H$ pylori infection, such as drinking or eating foods culturally more prevalent in Japan than in Western countries.

In summary, we have confirmed that gastric acid secretion has increased over the past 20 years from the 1970s in Japan irrespective of $H$ pylori infection, suggesting the presence of factors which increase gastric acid secretion other than the decreased infection rate of $H$ pylori.

This work was supported in part by Grants-in-Aid for Scientific Research from the Ministry of Education, Science, and Culture of Japan, and by a fund from the Shirakawa conference.

1 Collen MJ, Abdulian JD, Chen YK. Age does not affect basal gastric acid secretion in normal subjects or in patients with acid-peptic disease. Am 7 Gastroenterol 1994; 89: 712-6.

2 Kekki M, Sipponen P, Siurala M. Age behavior of gastric acid secretion in males and females with a normal antral and body mucosa. Scand f Gastroenterol 1983; 18: 1009-16.

3 Pilotta A, Vianello F, DiMario F, Plebani M, Farinati F, Azzini CF. Effect of age on gastric acid, pepsin, pepsinogen Azzini CF. Effect of age on gastric acid, pepsin, pepsinogen
group A and gastrin secretion in peptic ulcer patients. Gergroup A and gastrin secre.

4 Goldschmiedt M, Barnett CC, Schwarz BE, Karnes WE, Redfern JS, Feldman M. Effect of age on gastric acid secretion and serum gastrin concentrations in healthy men and women. Gastroenterology 1991; 101: 977-90.

5 Kimura K. Chronological transition of the fundic-pyloric border determined by stepwise biopsy of the lesser and greater curvatures of the stomach. Gastroenterology 1972; 63: 584-92.

6 Miyoshi A, Ohe K, Inagawa T. A statistical study on the age distribution of gastric secretion in patients with peptic ulcer. Hiroshima f Med Sci 1980; 29: 21-8.

7 Asaka M, Kimura T, Kudo M, Takeda H, Mitani S, Miyazaki T, et al. Relationship of Helicobacter pylori to serum pepsinogens in an asymptomatic Japanese population. Gastroenterology 1992; 102: 760-6.

8 Graham DY, Malaty HM, Evans DG, Evans DJ, Klein PD, Adam E. Epidemiology of Helicobacter pylori in an Adam E. Epidemiology of Helicobacter pylori in an ology 1991; 100: 1495-501.

9 Ormand JE, Talley NJ. Helicobacter pylori: controversies and an approach to management. Mayo Clin Proc 1990; 65: 414-26.

10 Graham DY. Helicobacter pylori: its epidemiology and its role in duodenal ulcer disease. F Gastroenterol Hepatol 1991; 6: $97-105$.

11 Roosendaal R, Kuipers EJ, Meuwissen SGM, Vandenbroucke-Grauls CMJE. H pylori and the birthcohort effect: evidence for continuous decrease of infection rates in childhood [abstract]. Gastroenterology 1996; 110: A242.

12 Haruma K, Goto T, Kawaguchi H, Kamata T, Kiyohira K, Ito $M$, et al. Marked decrease of $\mathrm{H}$ pylori infection in asymptomatic children in Japan [abstract]. Gastroenterology 1996; 110: A130.

13 Grant HW, Palmer KR, Kelly RW, Wilson NH, Misiewicz JJ. Dietary linoleic acid, gastric acid, and prostaglandin secretion. Gastroenterology 1988; 94: 955-9. 
14 Kinoshita Y, Yamashita Y, Chiba T. Correlation between serum pepsinogen concentration and gastric acidity meas1995; 10: 152-7.

15 Hasson LE, Engstrand L, Nyren O, Evans DJ Jr, Lindgren A, Bergstroem R, et al. Helicobacter pylori infection: independent risk indicator of gastric adenocarcinoma. Gastroenterology 1993; 105: 1098-103.

16 Talley NJ, Kost L, Hadded A, Zinsmeister AR. Comparison of commercial serological tests for detection of $\mathrm{H}$ pylor antibodies. F Clin Microbiol 1992; 30: 3146-50.

17 Glupczynski Y. Methodological aspects of serology for the diagnosis of $\mathrm{H}$ pylori infection. Eur $\mathcal{f}$ Gastroenterol Hepatol 1993; 5: S50-3.

18 Evans DJ Jr, Evans DG, Graham DY, Klein PD. A sensitive and specific serologic test for detection of Campylobacter pylori infection. Gastroenterology 1989; 96: 1004-8.

19 Samloff IM, Varis K, Ihamaki T, Siurala M, Rotter JI. Relationships among serum pepsinogen I, serum pepsinogen II,
and gastric mucosal histology. Gastroenterology 1982; 83: and gastri 204 .

20 Miki K, Ichinose M, Shimizu A, Huang SC, Oka H, Furihata C, et al. Serum pepsinogens as a screening test of extensive chronic gastritis. Gastroenterologia faponica 1987, 22: 33-41

21 Hunter FM, Correa P, Fonthan E, Ruiz B, Sobhan M, Samloff IM. Serum pepsinogens as markers of therapy for $\mathrm{H}$ pylori gastritis. Dig Dis Sci 1993; 38: 2081-6.

22 Wagner S, Haruma K, Gladziwa U, Soudah B, Gebel M, Bleck J, et al. $\mathrm{H}$ pylori infection and serum pepsinogen A pepsinogen $\mathrm{C}$, and gastrin in gastritis and peptic ulcer. $A m$ f Gastroenterol 1994; 89: 1211-8.

23 Feldman M, Cryer B, McArthur KE, Huet BA, Lee E. Effects of aging and gastritis on gastric acid and pepsin secretion in humans; a prospective study. Gastroenterology 1996; 110: 1043-52.

24 Satoh K, Kimura K, Yoshida Y, Ota Y, Taniguchi Y, Kihira $\mathrm{K}$, et al. Relationship between $\mathrm{H}$ pylori and atrophic gastri$\mathrm{K}$, et al. Relationship between H pylori and atropt
tis. Eur $\mathcal{7}$ Gastroenterol Hepatol $1994 ; 6$ : S85-8.

25 Kuipers EJ, Lee A, Klinkenberg KEC, Meuwissen SG. Review article: the development of atrophic gastritisReview article: the development of atrophic gastritisHelicobacter pylori and the effects of acid supp

26 Sakaki N, Momma K, Egawa N, Yamada Y, Kan T, Ishiwata J. The influence of Helicobacter pylori infection on the progression of gastric mucosal atrophy and occurrence of gastric cancer. Eur F Gastroenterol Hepatol 1995; 7: S56-62

27 Kasano T, Yoshida Y, Kihira K, Kimura K. Relationship between morphological and functional changes in the stomach with aging. Nippon Ronen Igakkai Zasshi 1991; 28: 606-10.

28 Satoh K, Kimura K, Sipponen P. Helicobacter pylori infection and chronological extension of atrophic gastritis. Eurf Gastroenterol Hepatol 1995; 7 (suppl 1): S11-5.

29 Schlewper RJ, Van der Werf SDJ, Vandenbroucke JP, Biemond I, Lamers CBHW. Seroepidemiology of gastritis in Japanese and Dutch working populations: evidence for the development of atrophic gastritis that is not related to the development of atrophic gast

30 Megraud F. Diagnosis of Helicobacter pylori. Baillieres Clin Gastroenterol 1995; 9: 507-18.

31 Feldman RA, Evans SJ. Accuracy of diagnostic methods used for epidemiological studies of Helicobacter pylori. Aliment Pharmacol Ther 1995; 9 (suppl 2): 21-31.
32 van de Wouw BA, de Boer WA, Jansz AR, Roymans RT. Serodiagnosis of Helicobacter pylori infection: an evaluation of a commercially available ELISA-IgG. Neth $f \mathrm{Med}$ 1995; 47: 272-7.

33 Kudo $M$, Asaka $M$, Kato $M$, Katagiri $M$, Kagaya $H$, Nishikawa $\mathrm{K}$, et al. Role of $\mathrm{H}$ pylori in chronic gastritis: a prospective study. F Clin Gastroenterol 1995; 21: S174-8.

34 Kuipers EJ, Uyterlinde AM, Nelis GF, Meijer CJLM, Pena AS, Meumissen SGM. Long term follow up of $\mathrm{H}$ pylori associate

35 Karnes WE, Samloff IM, Siurala M, Kekki M, Sipponen P, Kim SWR. Positive serum antibody and negative tissue staining for $\mathrm{H}$ pylori in subjects with atrophic body gastritis. Gastroenterology 1991; 101: 167-74.

36 Kuipers EJ, Uyterlinde AM, Pera AS, Hazenberg HJ, Bioemera $\mathrm{E}$, Lindeman $\mathrm{J}$, et al. Increase of Helicobacter pylori-associated corpus gastritis during acid suppression therapy: implications for long term safety. Am f Gastroenterol 1995; 90: 1401-6.

37 Yasunaga Y, Shinomura Y, Kanayama S, Yabu M, Nakanishi $\mathrm{T}$, Miyazaki T, et al. Improved fold width and increased acid secretion after eradication of the organism in $\mathrm{H}$ pylori acid secretion after eradication of the organism in H pylor

38 Ruiz B, Correa P, Fontham ETH, Ramakrishnan T. Antral trophy, $\mathrm{H}$ pylori colonization, and gastric $\mathrm{pH}$. Am $\mathcal{F}$ Clin Pathol 1996; 105: 96-101.

39 Division of Health and Nutrition, Department of Health and Medicine, Ministry of Health and Welfare, Japan. Current fapanese nutritional state. Tokyo: Daiichi Shupan Co. Ltd, 1994: 59.

40 Miller AB, Howe GR, Jain M, Craib KJP, Harrison L. Food items and food groups as risk factors in a case-control study of diet and colo-rectal cancer. Int 7 Cancer 1983; 32: 155-61.

41 Kakizoe T, Iwao S, Eto H, Kitai A, Kojima K, Furuta N, et al. Figures on cancer in fapan. Tokyo: Foundation for Promotion of Cancer Research. c/o National Cancer Center, 1993: 5

42 Logan RP, Walker MM, Misiewicz JJ, Gummett PA, Narim $\mathrm{QN}$, Baron JH. Changes in the intragastric distribution of H pylori during treatment with omeprazole. Gut 1995; 36: $12-6$.

43 Kuipers EJ, Lundell L, Klinkenberg KEC, Havu N, Festen $\mathrm{HP}$, Liedman B, et al. Atrophic gastritis and $\mathrm{H}$ pylori infection in patients with reflux esophagitis treated with omeprazole or fundoplication. N Engl f Med 1996; 334: 1018-22.

44 Tatsuta M, Iishi H, Yamamura H, Yamamoto R, Taniguchi $\mathrm{H}$. Enhancement by tetragastrin of experimental induction of gastric epithelium in the duodenum. Gut 1989; 30: 311-5.

45 Khulusi S, Badve S, Patel P, Lloyd R, Marrero JM, Finlayson $\mathrm{C}$, et al. Pathogenesis of gastric metaplasia of the human duodenum: role of $\mathrm{H}$ pylori, gastric acid, and ulceration. Gastroenterology 1996; 110: 452-8.

46 Kawai K, Shirakawa K, Misaki F, Hayashi K, Watanabe Y. Natural history and epidemiologic studies of peptic ulcer disease in Japan. Gastroenterology 1989; 96: 581-5.

47 Furuya S. The endoscopic and functional evaluation of reflux esophagitis-especially divided with reference to age. f Kyoto Pre Med Coll 1990; 99: 1325-43. 